\title{
Pandemic blows lid off laws limiting mercury in vaccines
}

As public health officials around the world scramble to protect their citizens from swine flu, some in the US are grappling with an additional issue: state laws that limit the use of a mercury preservative in vaccines.

Between 2004 and 2006, six statesCalifornia, Delaware, Illinois, Missouri, New York and Washington — enacted laws limiting the use of the preservative, thimerosal, in flu vaccines and other shots given to children and pregnant women. The move was made in response to fears that thimerosal might cause neurological conditions such as autism.

This fall, however, all six states temporarily lifted the restriction in response to the outbreak of pandemic swine flu and the shortage of H1N1 vaccine. Many of the available vaccines came in multidose vials, which are quicker to manufacture and contain thimerosal to prevent contamination with repeated inserts of a needle.
Although the laws allow for such temporary suspensions, many people question their utility in the first place, given their feeble scientific foundation. The laws are "absolutely not" supported by research, says Diane Peterson, an associate director at the Immunization Action Coalition, a vaccine advocacy group in St. Paul, Minnesota. Even in 2004, before the laws were enacted, a US Institute of Medicine panel found that the scientific evidence did not support a link between thimerosal-containing vaccines and autism, and several subsequent studies have backed up that conclusion ( $N$. Engl. J. Med. 357, 1281-1292; 2007)

But vaccine experts say that antithimerosal advocates remain vocal. Mary Selecky, Washington's secretary of health, received a flurry of complaints after she suspended the thimerosal restrictions in September. "They were quite angry at me," she says. "Clearly, folks were very pointed about feeling I was wrong."
Peterson is concerned that the thimerosal bans have helped fuel a backlash against vaccination. "The laws have contributed to the doubts people have about the safety of vaccines," she says. An ABC/Washington Post poll from October found that nearly half of parents did not intend to vaccinate their children against swine flu, in part because of safety concerns.

But as the scientific evidence mounts, laws limiting thimerosal have been harder to get through state legislatures. This year alone, advocacy groups and individuals in 12 states tried-and failed - to pass similar restrictions, according to Peterson. What's more, the laws are mostly redundant, as thimerosal was removed from nearly all vaccines by 2001 . Even so, the six states' thimerosal bans remain on the books; Washington's is scheduled to go back into effect in March.

Charlotte Schubert, Washington, DC

\section{In prevention push, AIDS program prioritizes research}

In early December, the US President's Emergency Plan for AIDS Relief-better known as PEPFAR — released a new strategy that prioritizes HIV prevention, partnerships with national governments and operations research. The five-year strategy represents a major shift from PEPFAR's initial goal of getting millions of people on antiretroviral treatment.

Research has been a component of PEPFAR since its inception, but it was previously "neglected," said US Global AIDS Coordinator Eric Goosby at a Kaiser Family Foundation town hall meeting on 4 December. Now, he says, it's a "high priority." Exactly how much money will be available for research and how those funds will be distributed is not yet clear.

In the town hall session, Goosby emphasized that operations research, which is used to assess the effectiveness or impact of programs, needs to play a larger part. Operations research, the strategy points out, does not include clinical or basic research. It is also distinct from monitoring and evaluation. "With operations research, you're making a comparative evaluation rather than just charting trends," says Willard Cates, president of research at Family Health International, a public health and development organization that receives PEPFAR funds.

These comparative assessments will be especially important in the arena of prevention, says Nandini Oomman, an HIV expert at the Center for Global Development, an independent think tank in Washington, DC, that aims to reduce global poverty. Prevention strategies exist, she says, but "we haven't done the good research job of trying to understand how these can be offered in different combinations to maximize prevention efforts and to bring them to scale."

For the past two years, PEPFAR has dedicated $\$ 40$ million a year to operations research out of its annual $\$ 6.6$ billion budget. In 2008, PEPFAR decided to revise its operations research program to improve quality and coordination and to eliminate redundancies. That revision is ongoing. In the coming years, PEPFAR will encourage studies that involve multiple countries and coordinated methodologies.

According to Ronald Gray, an epidemiologist at Johns Hopkins University in Baltimore who works in Uganda, the program is in need of revision. Last year, he and his colleagues received PEPFAR funding through the Atlanta-based US Centers for Disease Control and Prevention (CDC) to look at male circumcision as an HIV prevention strategy. The long-distance micromanagement was such a "bureaucratic nightmare" that Gray and his colleagues ultimately decided to return the money.

The new emphasis on research "is a step forward," Gray says. But, he warns, "if this is going to be managed from Atlanta... then it's going to be a very bureaucratic process and possibly dysfunctional."

Not all of PEPFAR's research funds are distributed by the CDC; the US National Institutes of Health received $\$ 4.9$ million from the PEPFAR office last year. That money went to support, among other research, a study that looked at two ways of managing HIV infectionviral load testing versus the current standard of care, CD4 testing and clinical evaluation.

Part of the new commitment to research will entail making more PEPFAR data publicly available so that researchers can mine it. How and when that data will be accessible is still up in the air. The new strategy does not contain any information about how the new priorities will be implemented.

PEPFAR's new strategy also emphasizes coordination with national governments. PEPFAR programs must be "country owned and country driven," Goosby said at the 4 December meeting. He emphasized that national governments take a leadership role in responding to the epidemic. Given that government corruption is a problem in many PEPFAR countries, careful accounting will be important, says Cates.

Overall, the new strategy is a good first step, Oomman says. "This is a major shift in the direction that many of us were calling for." But it remains to be seen whether the priorities outlined in the strategy will be implemented. "The proof of the pudding," says Cates, "is over the next several years."

Cassandra Willyard, New York 